\title{
REVIEW
}

\section{Young people, place and identity}

Peter E. Hopkins

Abingdon: Routledge, 2010, 311pp, £23.99 (pbk)

ISBN: 9780415454391

\author{
Anne Green* \\ University of Warwick
}

\begin{abstract}
At the time of writing this review young people are in the news with youth unemployment in the UK exceeding one million. It is likely that more researchers will be turning their attention to young people and their lives. Those researchers requiring a reference book before starting out on studies of young people (i.e. defined here as those aged between 16 and 25 years), or seeking to find out more about aspects of young people's everyday lives, would do well to turn to this comprehensive volume as a key source at the outset. Primarily this is a book to dip in and out of, rather than to be read from cover to cover. Indeed, it is organised to allow readers to approach it in this way, as each chapter is constructed in a self-contained fashion to address a particular topic, with engaging text, boxes setting out examples or providing more detailed supporting information, and with key themes, project ideas, and suggestions for further reading (with a sentence summarising the scope of each) at the end. This format is likely to make the book especially appealing for undergraduates and postgraduates across a range of social science disciplines, including geography, sociology, social policy, politics and cultural studies. While the book has a primarily UK focus, it draws on examples and literature from other parts of Europe, the USA and beyond. It addresses contemporary concerns and issues, rather than considering young people in historical perspective.
\end{abstract}

The first chapter, entitled Introduction, does an excellent job of sketching the scope and structure of the book and sets out its overall aim: "to explore the ways in which experiences of being young are mediated by different places and social identities" ( $p$. 1). It outlines the three key categories - age, identity and place - that are central to the book. It distinguishes between chronological, physiological and social approaches to age, and outlines how these different approaches to young people's lives influence how they construct and contest their identities at different times and in different places. It sets out various facets of identities, and explores how identities are constructed through social relations. It goes on to highlight key components of similarity and difference and discusses the relational, intersectional and dynamic nature of identity. It introduces place both as an objective unique location and in a subjective relational 
fashion as part of a complex web of flows and processes with permeable boundaries. Importantly it argues that: "the places inhabited and associated with young people matter; geography matters" (p. 11). Place influences identity, and place can be an important marker of identity. Having provided introductions to concepts of age, identity and place, three frameworks for studying young people are introduced: first, a lifecourse approach; secondly, intergenerationality; and thirdly, intersectionality. If you only want to read one chapter, make it the first, as it sets the overall context, but better still, read the first chapter and couple of others looking at particular topics - according to your interests - in more detail.

Following the Introduction, the book is organised in three parts. Part 1 is concerned with research methods and ethics. The two chapters in this part are 'must reads' for anyone contemplating a research project with young people, especially if they have little previous research experience, because these chapters set out key issues in a step-by-step fashion. Not only do they provide 'good practice' guidance, but the reasons why particular issues are important in the research process are outlined. Chapter 2 considers young people's place in research and sets out possible relationships between a researcher and the young people being researched. It discusses the advantages and disadvantages of various approaches used in research about young people, identity and place, including verbal, observational, visual and textual, and participatory approaches. It also sets out considerations for researchers to keep in mind when adopting particular methods - for example, key issues to take into account in focus group work with young people. It also includes guidance on issues of data analysis and dissemination, including strategies for establishing rigour and principles for evaluating qualitative research. Chapter 3 is concerned with methodological and ethical considerations. Box 3.1 sets out ten topics for consideration in carrying out research with young people, so providing a useful checklist for a researcher starting out on a research project. The chapter also introduces issues of informed consent, confidentiality and anonymity, and discusses the pros and cons of incentivising participation in research. Importantly, the need for consideration of a range of contextual and methodological factors at all points in the research process, not just at the start, is emphasised.

Part II of the book is organised in accordance with five scales from the body, through the home, neighbourhood and community, the nation, and the global, with each scale accounting for a separate chapter. This is where the reader might choose to dip in and out, according to his/her particular interests. Discussion in all of the constituent chapters is necessarily selective. So, for example, Chapter 6 on 'Neighbourhood and community' starts by outlining how these terms can be defined in symbolic and physical ways. It then discusses neighbourhoods and territorialism noting that territorialism tends to be strongest in disadvantaged neighbourhoods and communities where limited opportunities, restricted horizons and perhaps difficult family circumstances shape young people's engagement with their local area. It then addresses the theme of neighbourhoods and poverty, and makes the point that young people who live in neighbourhoods where poverty dominates suffer from a lack of services and opportunities, yet often choose to live locally and to spend much of their time within the public spaces of their neighbourhood. Finally it considers the themes of communities and faith, and communities and crime.

Part III of the book is concerned with what are termed 'themes and sites'. Again, most probably the reader will choose to dip into this section according to his/her interests. The themes and sites covered in Chapters 9 to 12 are institutions (including school, university and residential care); public space and the street; migrations, mobilities and transitions (incorporating topics from fleeing persecution to the transition to adulthood and the gap year); and urban-rural. As in Part II, only selected 
topics are included in each of the chapters, presumably chosen to highlight different aspects of young people's lives.

Chapter 13 presents the Conclusions from the preceding chapters. This is a difficult task given the range of discussion and the amount of ground covered. As the author notes at the outset: "I have tried to highlight something of the breadth of young people's lives" (p. 265). This diversity amongst young people who share similarities in terms of age is attributed to the differences in their experiences, identities and places where they live. Overall, this is a short chapter, and a mere page is set aside for considering what the future holds for young people. Yet the final point made is an important one: "Future research about young people, place and identity should ideally be theoretically informed and empirically grounded whilst also being sensitive to the various ethical issues arising in engaging with young people in research" (p. 273).

Ultimately, this is a useful book for reference. It is accessible and nicely presented. It draws on a wide range of sources to illustrate key arguments and to illuminate good practice. The first chapter is well worth reading. Part I on methods and ethics is practical and helpful and should be referred to when contemplating and executing a research project. The remaining chapters are best seen as a resource, to be dipped into as and when required - they provide useful introductions to particular themes and topics, with suggestions for further reading for those who wish to deepen the knowledge they have gained from the book.

* Correspondence address: Institute for Employment Research, University of Warwick, Coventry, CV4 7AL. Email: Anne.Green@warwick.ac.uk 